УДК 621.452.3.034.022:519.872.8

doi: 10.32620/aktt.2021.4sup1.04

\title{
C. A. EBCEEB
}

ГП «Ивченко-Прогресс», Украчна

\section{РАСЧЕТНАЯ ОЦЕНКА ВЛИЯНИЯ НЕРАВНОМЕРНОСТИ РАСПЫЛА ТОПЛИВА НА ПОЛЕ ТЕМПЕРАТУР ГАЗА НА ВЫХОДЕ ИЗ КАМЕРЫ СГОРАНИЯ ГТД}

\begin{abstract}
В данной работе представлены результаты численного моделирования течения газа с горением распьленного жидкого топлива (использовалась модель равновесного горения рdf наряду с моделью частично перемешанной смеси) в кольцевой камере сгорания газотурбинного двигателя. Численное моделирование выполнялось в расчетном комплексе ANSYS Fluеnt. Целью расчетов являлось оценка влияние неравномерности распыла топлива заданной в конструкторской документации и коксования деталей фронтового устройства на радиальную и окружную неравномерность поля температур газа на выходе из камеры сгорания. При моделировании использовалась ранее верифицированная модель турбулентности $k$ - $\varepsilon$ с функииональной зависимостью турбулентного числа Шмидта Sc от температуры газа которая была реализована в расчетном комплексе ANSYS Fluent с помощью функции пользователя $(U D F)$. В связи с тем, что топливная форсунка и завихритель, представляют достаточно сложную схему распыливания, не позволяющую расчетным путем оценить количество топлива, поступающего через отверстия в колпачке завихрителя была изготовлена установка и проведены испытания по определению количества топливовоздушной смеси, распределяемой по отверстиям колпачка завихрителя. Экспериментальные значения распределения топливовоздушной смеси через отверстия в колпачке завихрителя в дальнейшем использовались для выполнения численного моделирования горения в камере сгорания. Численное моделирование проводилось с секторной неравномерностью равной $0 \%$, $50 \%$ (максимально допустимая согласно конструкторской документации) и при коксовании отверстий колпачка завихрителя. В результате проведенных расчетов установлено, что секторная неравномерность 50 \% оказывает не существенное влияние по отношению к секторной неравномерности 0\% на радиальную неравномерность поля температур газа на выходе из камеры сгорания, при этом окружная неравномерность на выходе из камеры сгорания выросла на 1,6 \% по отношению к секторной неравномерности $0 \%$. При коксовании отверстий колпачка завихрителя значение радиальной эпюра на выходе из камеры сгорания увеличивается на 1,2\%, а значение окружной неравномерности увеличивается на $4 \%$.
\end{abstract}

Ключевые слова: распыл топлива; секторная неравномерность; камера сгорания; турбулентное число Шмидта; поле температур газа; компьютерное моделирование; UDF; ANSYS Fluеnt.

\section{Введение}

Процесс подачи и распыла топлива играет большую роль в обеспечении надлежащих характеристик процесса горения. Для камер сгорания (КС) перспективных ГТД эта роль только усилится, поскольку к авиационным двигателям и промышленным газотурбинным установкам предъявляются все возрастающие требования в отношении снижения выбросов вредных веществ, а также ввиду необходимости использования синтетических топлив и топлив более тяжелых фракций $[1,2]$.

Используя современные методы вычислительной аэрогидродинамики (ВАГД) можно оценить влияние неравномерности распыла топлива на поле температур газа за КС. Методы ВАГД использует в качестве базовой физическую модель вязкого газа и ее математическую модель - систему осредненных по Рейнольдсу уравнений Новье-Стокса (RANS), включающих уравнение сохранение массы, уравнения сохранения количества движения и энергии. Для замыкания системы осредненных по Рейнольдсу уравнений использовалась модель турбулентности. Дискретизация дифференциальных уравнений в частных производных осуществляется методами конечных объемов.

В данной работе представлены результаты расчета влияния неравномерности распыла топлива на температурное поле газа на выходе из КС.

При расчете была применена ранее верифицированная на ГП «Ивченко-Прогресс» модель турбулентности и макрос (User Defined Functions (UDF) функция, определяемая пользователем) для определения число Шмидта в каждой ячейке расчетного домена в виде функции температуры $\mathrm{Sc}=\mathrm{f}(\mathrm{T})$, что в свою очередь значительно повышает точность расчета окружной неравномерности поля температур газа на выходе из КС при использовании одного сектора КС (сектор 1/22) [3].

(C) С. А. Евсеев, 2021 
Объектом исследования является течение газа с горением распыленного топлива в КС (сектор 1/22) газотурбинного двигателя (рис. 1).

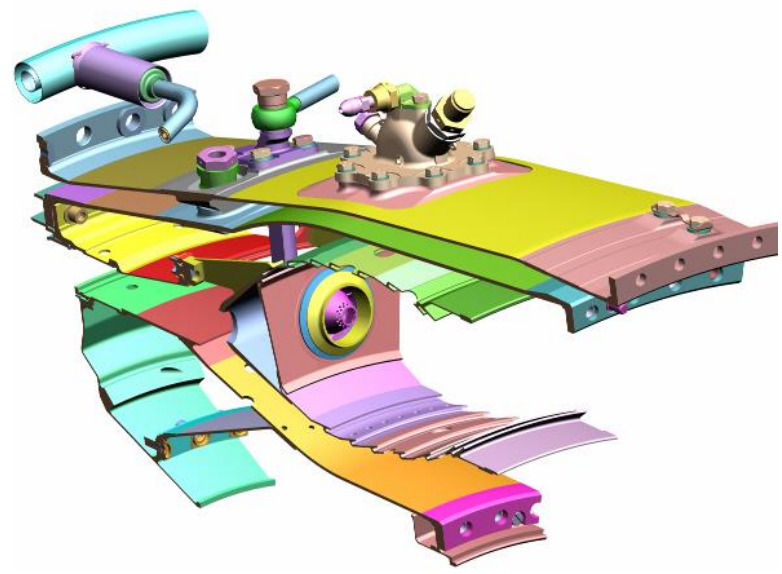

Рис. 1. Геометрия одногорелочного сектора КС

\section{1. Численный метод и граничные условия}

Как показывает опыт, эффективность процесса сжигания жидкого топлива в камерах сгорания двигателей, так же, как и совершенство ряда технологических процессов, часто в значительной мере зависит от качества распыливание жидкостей.

Процесс превращения некоторого объема жидкости в совокупность большого числа мелких капель называется распыливанием, а устройство при помощи которого происходит распыливание называется форсункой.

Серьезным дефектом, ограничивающим ресурс, надёжность ухудшающим экологичность газотурбинного двигателя (ГТД) $[4,5]$, является засорение каналов распыливающих деталей форсунок (колпачка), коллектора камеры сгорания продуктами коксования, которые образуются при нагревании проходящего через него топлива за счет окисления молекул углеводородного топлива растворенным в нем кислородом с образованием продуктов большой молекулярной массы и их дальнейшей полимеризацией в виде коксоподобных соединений, отложения которых выпадают на стенки деталей распыляющего устройства (рис. 2), что в свою очередь может оказывать влияние на поле температур газа на выходе из КС.

Целью данной работы является определение влияния неравномерности распыла топлива (коксование отверстий перфорации на колпачке) на поле температур газа на выходе из КС.

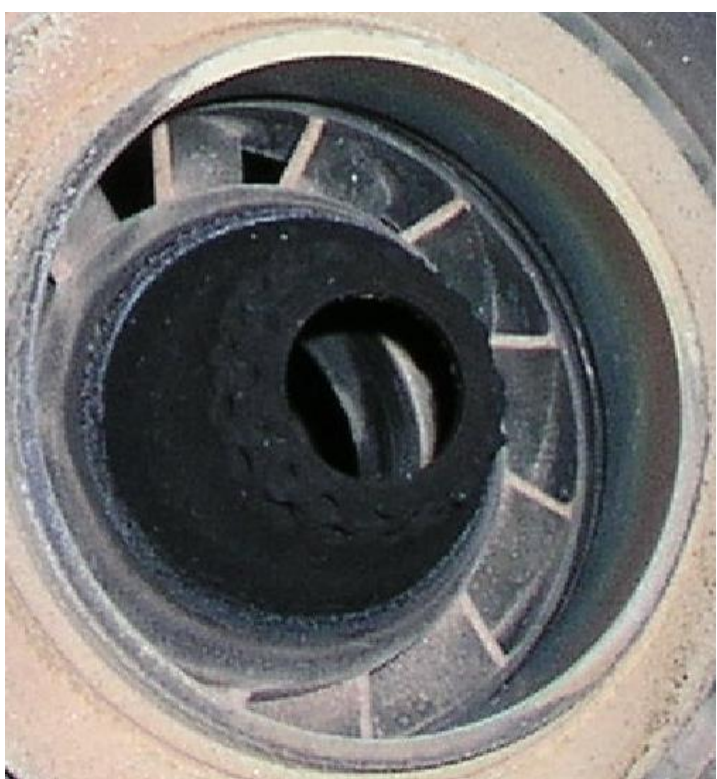

Рис. 2. Распыляющее устройство КС

\section{1. Физико-математическая постановка задачи}

Для моделирования течения газа с горением керосина в исследуемой области использовался программный комплекс ANSYS Fluent 2021 R1, в котором реализовано численное решение осредненных по Рейнольдсу уравнений Навье-Стокса (RANS), включающих уравнение сохранение массы (уравнение неразрывности), уравнения сохранения количества движения и энергии. Для замыкания системы осредненных по Рейнольдсу уравнений использова-

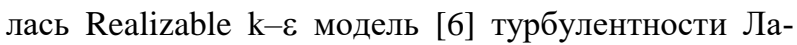
ундера-Сполдинга. Дискретизация дифференциальных уравнений в частных производных осуществляется методами конечных (контрольных) объемов.

Граничные условия на твердой стенке для нахождения сдвиговых напряжений, кинетической энергии турбулентности (ТКЕ) и скорости диссипации ТКЕ определялись с помощью пристеночной функции (Standard Wall Functions).

Использовалась модель горения не перемешанной смеси (функция Шваба - Зельдовича / функция плотности распределения вероятности (ФПВ (PDF)) / предвычисленные ФПВ-таблицы).

При моделировании движения, теплообмена и испарение капель распыленного топлива применялась модель дискретной фазы (Discrete Phase Model).

В отношении газовой фазы принимались следующие основные допущения:

- газовая фаза представляет собой многокомпонентную химически реагирующую смесь термодинамически совершенных газов, входящих в состав топлива, окислителя и продуктов сгорания; 
- течение газа трехмерное, турбулентное, несжимаемое [7], существенно дозвуковое;

- объемной вязкостью, вязким нагревом и лучистым теплообменом пренебрегаем;

- объемом, занимаемым каплями, и влиянием капель на характеристики турбулентности пренебрегаем.

\section{2. Построение расчетной сетки}

Построение расчетных сеток является неотъемлемой составляющей и важным этапом в задаче численного моделирования течений жидкости и газа вокруг тел сложной формы.

Для задач численного моделирования течений жидкости и газа можно использовать различные типы расчетных сеток, включая криволинейные блочно-структурированные сетки, тетраэдральные сетки, гибридные сетки, состоящие их тетраэдров с призматическими слоями вблизи тел с граничными условиями прилипания, общие неструктурированные сетки, состоящие из тетраэдров (tetrahedral), призм, пирамид и гексаэдров (hexahedral), полиэдральные сетки (polyhedral), состоящие из невыпуклых многогранных ячеек с произвольным числом граней, а также адаптивные декартовы сетки с иерархической структурой, основанной на восьмеричных деревьях и с использованием усеченных ячеек.

Для каждого из типа сеток можно указать свои преимущества и недостатки. Для тетраэдральных сеток существуют быстрые и надежные алгоритмы построения в случае тел сложной формы, однако они не являются самым эффективным инструментом при наличии пограничных слоев и слоев смешения. Сравнительно простой и эффективный способ исправления базовых недостатков тетраэдральных сеток основан на построении слоев сильно анизотропных призматических сеток в пограничных слоях и других областях анизотропии решений. Криволинейные блочно-структурированные сетки позволяют получать численные решения с высокой степенью точности и достоверности, но их построение до сих пор не поддается автоматизации и требует длительно времени и больших трудозатрат. Методы построения неструктурированных полностью гексаэдральных сеток в настоящее время активно развиваются, но проблема их автоматического построения еще не решена.

Для геометрически сложных расчётных областей удобнее использовать тетраэдрические расчётные сетки: их построение гораздо менее трудоёмко. Однако из-за принципиальной несогласованности с направлением течения тетраэдрические сетки обеспечивают меньшую точность расчёта (частично этот недостаток можно компенсировать увеличением порядка точности схемы аппроксимации конвективных членов и вычислением градиентов по значениям в узлах ячеек).

Кроме того, при одинаковом разрешении тетраэдрическая сетка (tetrahedral) имеет значительно больше элементов по сравнению с гексаэдрической (hexahedral) и полиэдральные сетки (Polyhedral) (рис. 3). Поэтому применение тетраэдрической сетки не экономично с точки зрения использования вычислительных ресурсов.

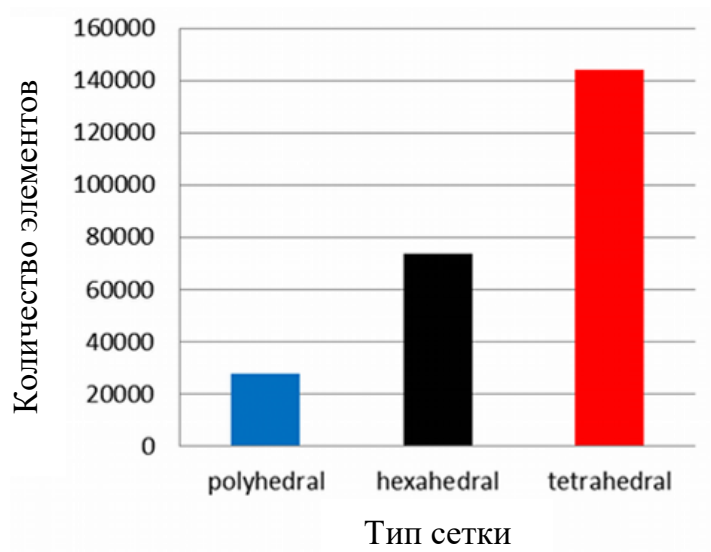

Рис. 3. Сравнительная диаграмма количества элементов от типа сетки

На рис. 4 представлена диаграмма на которой показано какое количество итераций нужно выполнить для достижения устойчивого значения падения давления в зависимости от типа сетки.

Расчётная область пространства, включающая одногорелочный сектор КС, геометрически сложна, в частности, многосвязна и разномасштабна. Для данной задачи была выбрана полиэдральная сетка (Polyhedral).

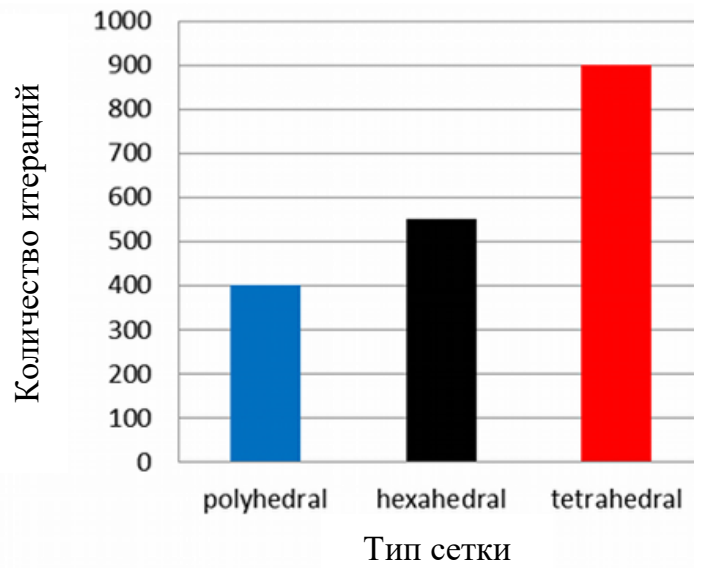

Рис. 4. Сравнительная диаграмма количества итераций до полной сходимости давления в зависимости от типа сетки 
В соответствии с изложенными выше принципами расчётных сеток была построена сетка для оценки поля температур газа на выходе из КС в зависимости от неравномерности подачи топлива тем самым имитируя коксование деталей форсунки.

Расчётная сетка с учетом адаптации в области смесительных отверстий содержит 30 млн. ячеек (рис. 5).

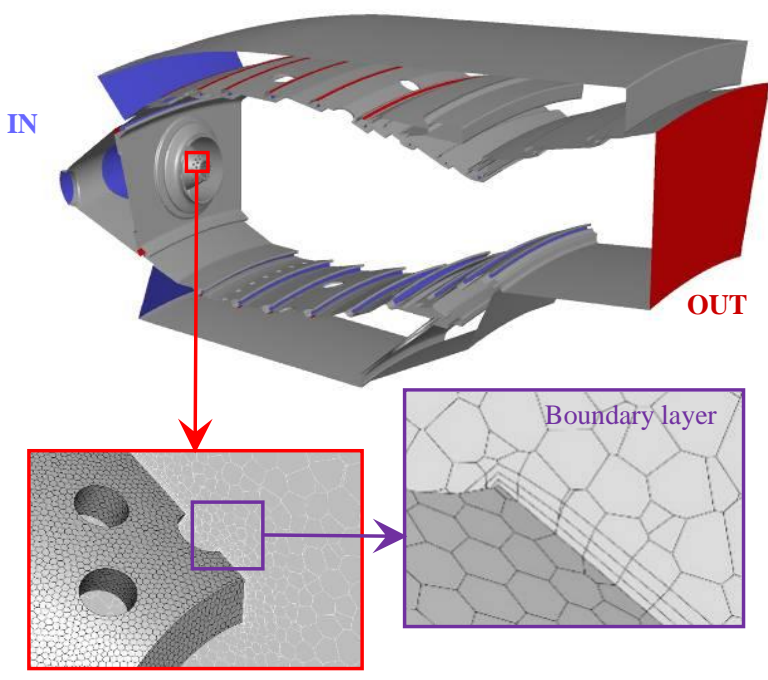

Рис. 5. Численная сетка

\section{3. Граничные условия}

На рис. 5 показана условная схема задания граничных условий.

На входной границе (IN) задавался массовый расход воздуха Gв, полная температура $\mathrm{T}^{*}$, интенсивность турбулентности и отношение турбулентной к динамической вязкости.

На выходной границе (OUT) - избыточное давление, полная температура возвратного течения, интенсивность турбулентности возвратного течения и отношение турбулентной вязкости к динамической вязкости возвратного течения.

На боковых гранях (Periodic) задавался тип граничных условий Rotational-periodic.

\section{4. Численный метод решения}

Настройки решателя программы ANSYS Fluent, реализующие численный метод решения управляющих уравнений, приведены в таблице 1.

Метод вычисления градиентов по значениям в узлах является более точным, чем метод вычисления градиентов по значениям в центрах ячеек.
Таблица 1

Численный метод решения

\begin{tabular}{|c|c|}
\hline $\begin{array}{c}\text { Аспект численной } \\
\text { процедуры }\end{array}$ & $\begin{array}{c}\text { Опция программы } \\
\text { Fluent }\end{array}$ \\
\hline $\begin{array}{l}\text { Solver } \\
\text { (Решатель) }\end{array}$ & $\begin{array}{l}\text { Segregated } \\
\text { (Раздельный) }\end{array}$ \\
\hline $\begin{array}{l}\text { Gradient Option } \\
\text { (Метод вычисле- } \\
\text { ния градиентов) }\end{array}$ & $\begin{array}{l}\text { Node-Based } \\
\text { (По значениям в узлах) }\end{array}$ \\
\hline $\begin{array}{l}\text { Pressure-Velocity } \\
\text { Coupling } \\
\text { (Метод коррекции } \\
\text { давления } \\
\text { по скорости) }\end{array}$ & SIMPLE \\
\hline $\begin{array}{l}\text { Equations } \\
\text { (Решаемые } \\
\text { уравнения) }\end{array}$ & $\begin{array}{l}\text { Flow (4 уравнения) } \\
\text { Turbulence ( } 2 \text { уравнения) } \\
\text { Energy (1 уравнение) } \\
\text { PDF (2 уравнения) } \\
\text { Итого: (9 уравнения) } \\
\end{array}$ \\
\hline $\begin{array}{l}\text { Discretization } \\
\text { (Схема } \\
\text { дискретизации) }\end{array}$ & $\begin{array}{l}\text { First Order Upwind (1-го по- } \\
\text { рядка точности «против } \\
\text { потока») или Third Order } \\
\text { MUSCL (3-го порядка «про- } \\
\text { тив потока») }\end{array}$ \\
\hline $\begin{array}{l}\text { Under-Relaxation } \\
\text { (Коэффициенты } \\
\text { нижней } \\
\text { релаксации) [8] }\end{array}$ & $\begin{array}{l}\text { Pressure - } 0,2 ; \\
\text { Momentum - } 0,5 ; \\
\text { Energy - 0,9; } \\
\text { Temperature - 0,9; } \\
\text { Mean Mixture Fraction - } 0,9 ; \\
\text { Mixture Fraction Variance - } 0,8 ; \\
\text { Discrete Phase Sources - 0,2; } \\
\text { Остальные - по умолчанию. }\end{array}$ \\
\hline
\end{tabular}

\section{2. Результаты исследований}

Решалась задача численного моделирования течения газа с горением распыленного жидкого топлива в кольцевой камере сгорания ГТД. При расчете была применена ранее верифицированная на ГП «Ивченко-Прогресс» модель турбулентности и макрос (UDF) [3].

Традиционная для камер сгорания нашего предприятия конструкция фронтового устройства, включающего в себя топливную форсунку и завихритель, предполагает достаточно сложную схему распыливания, не позволяющую расчетным путем оценить количество топлива, поступающего через отверстия в колпачке завихрителя. Для решения этой задачи была изготовлена установка и проведены испытания (рис. 6) по определению количества топливовоздушной смеси, распределяемой по элементам колпачка завихрителя. Экспериментальные значения распределения топливовоздушной смеси через отверстия в колпачке завихрителя в дальнейшем использовались для выполнения численного моделирования горения в КС. 


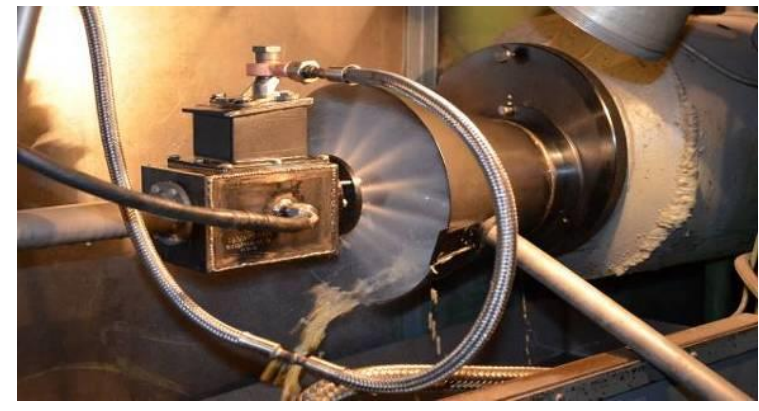

$\mathbf{a}$

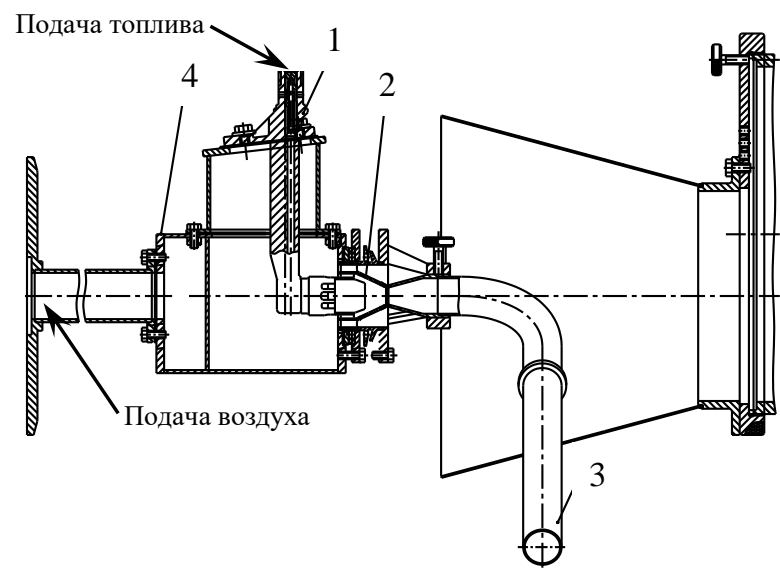

б

Рис. 6. Установка для исследования распределения топливовоздушной смеси по отверстиям колпачка завихрителя:

а - установка; б - схема установки;

1 - форсунки; 2 - завихритель; 3 - патрубок разделения смеси; 4 - приспособление

На первом этапе был выполнен расчет для оценки неравномерности поля температур газа на выходе из КС с секторной неравномерностью 0 \% (рис. 7).

Согласно конструкторской документации (КД) на форсунку, секторная неравномерность не должна превышать 50 \%. Поэтому вторым этапом был выполнен расчет с максимальной неравномерностью распыла топлива $50 \%$ (рис. 8).

На третьем этапе был выполнен расчет оценки неравномерности поля температур газа на выходе из КС с имитацией коксования отверстий в колпачке завихрителя (как крайний случай, отсутствующий на практике). Численное моделирование выполнялось с условием, что топливовоздушная смесь не поступает через отверстия перфорации в колпачке, а вся она идет через центральное отверстие колпачка завихрителя.

Результаты численного моделирования течения газа с горением распыленного жидкого топлива в кольцевой камере сгорания ГТД представлен на рис. 9, 10 и 11.

Для повышения точности моделирования неравномерности поля температур на выходе из каме- ры сгорания проведен численный эксперимент по исследованию влияния неравномерности распыла топлива на величину неравномерности поля температур газа на выходе из КС (рис. 11).

Из рисунков видно, что секторная неравномерность распыла топлива $50 \%$ по сравнению с секторной неравномерностью $0 \%$ слабо влияет на максимальное значение радиальной эпюры при этом коксование увеличило максимальное значение радиальной эпюры на 1,5 \% по сравнению с секторной неравномерностью $0 \%$.

Что касается окружной эпюры то она увеличивается с ростом секторной неравномерности. При секторной неравномерности $50 \%$ максимальное значение окружной эпюры выросло на 1,6 \%, а при коксовании на $4 \%$ по сравнению с секторной неравномерностью $0 \%$.

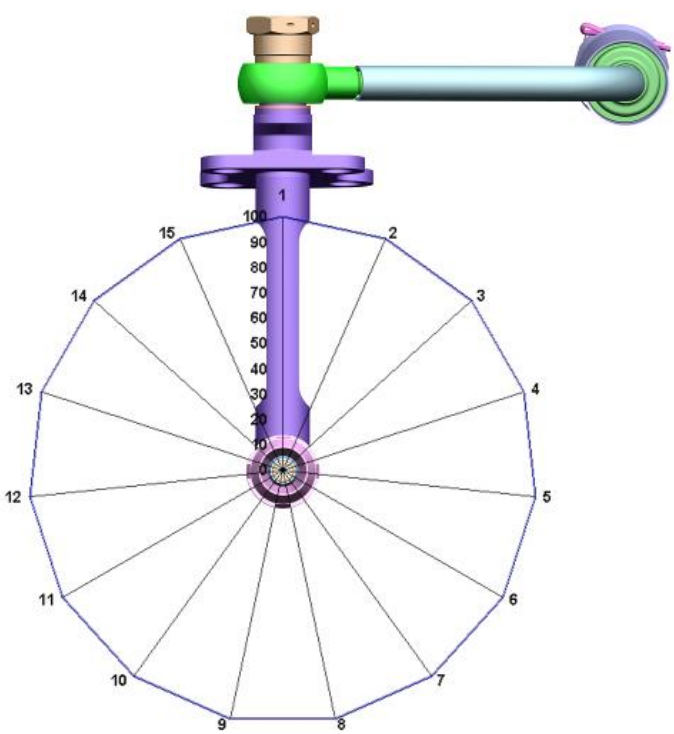

Рис. 7. Секторная неравномерность $=0 \%$

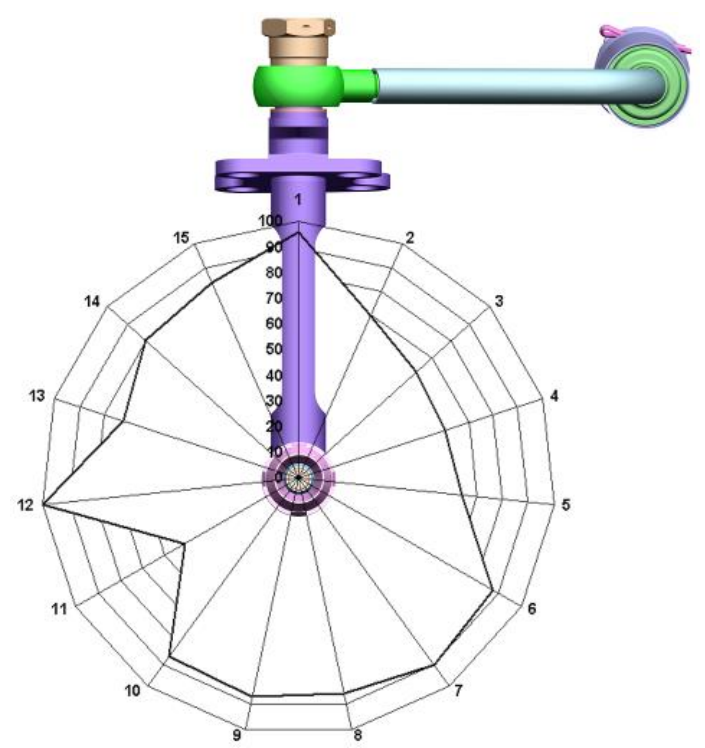

Рис. 8. Секторная неравномерность $=50 \%$ 


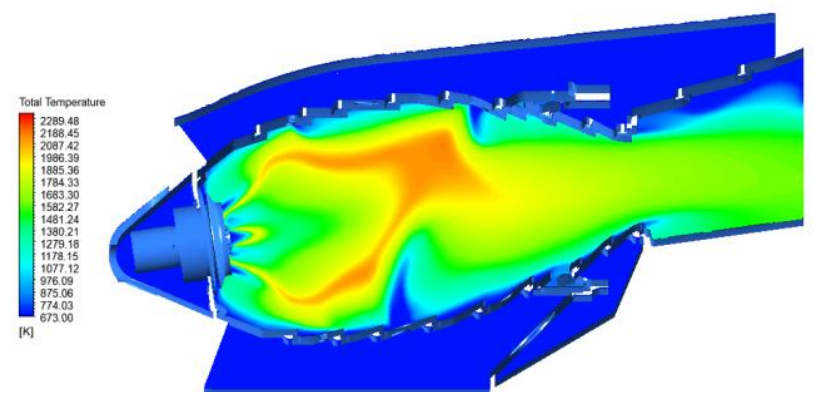

Секторная неравномерность $0 \%$

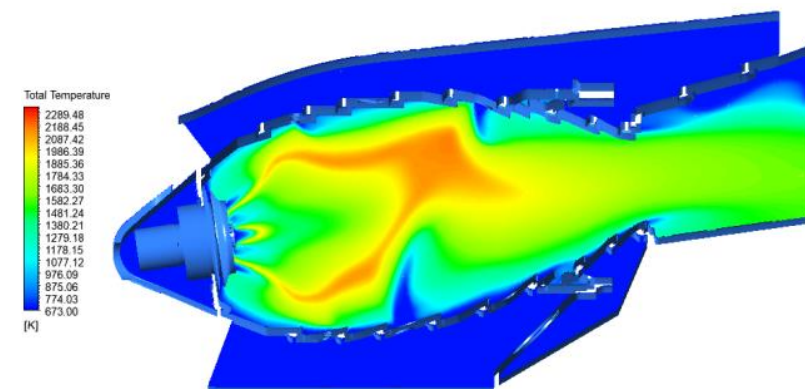

Секторная неравномерность $50 \%$

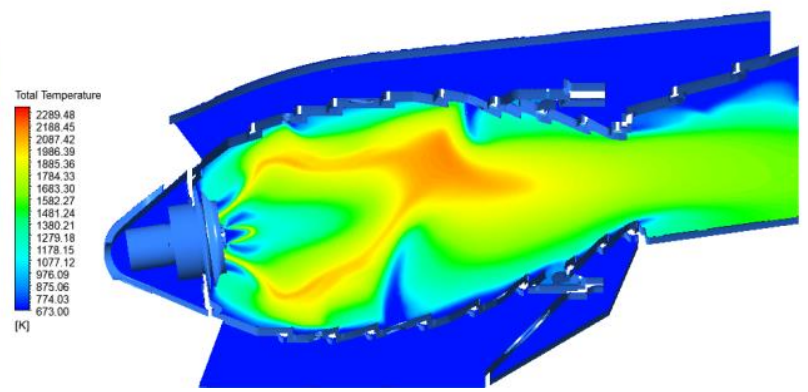

Коксование отверстий в колпачке завихрителя
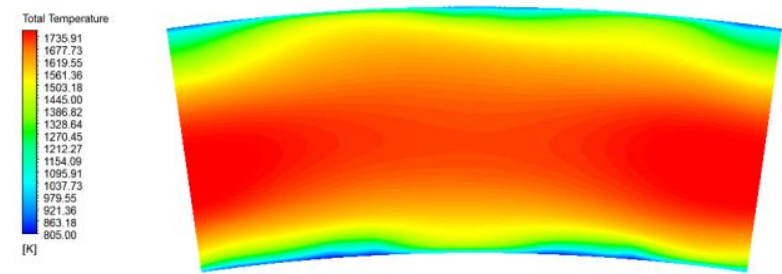

Секторная неравномерность $0 \%$

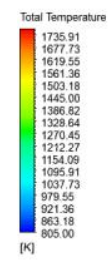

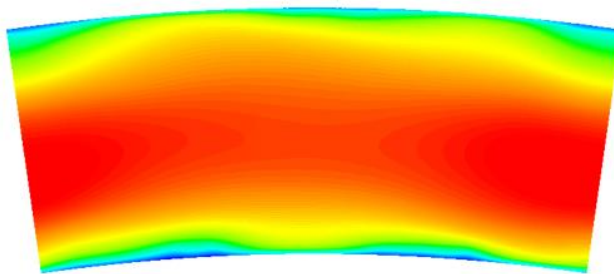

Секторная неравномерность $50 \%$
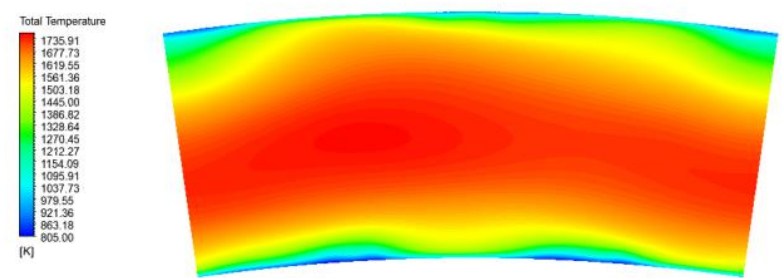

Коксование отверстий в колпачке завихрителя

Рис. 9. Температурное поле газа в меридиональном и выходном сечении камеры сгорания с различной секторной неравномерностью и имитацией коксования 


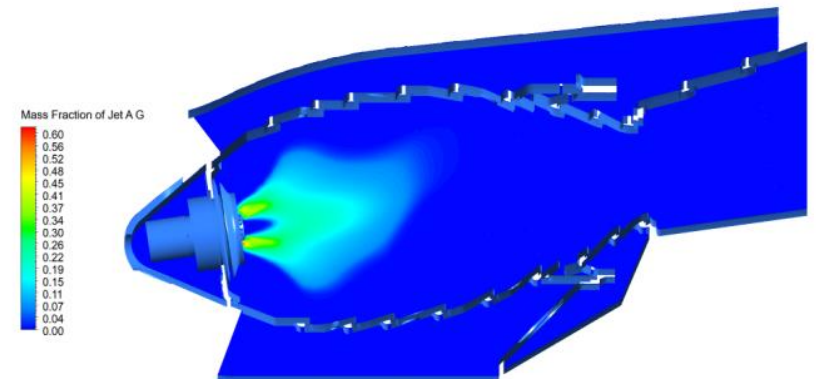

Секторная неравномерность $0 \%$

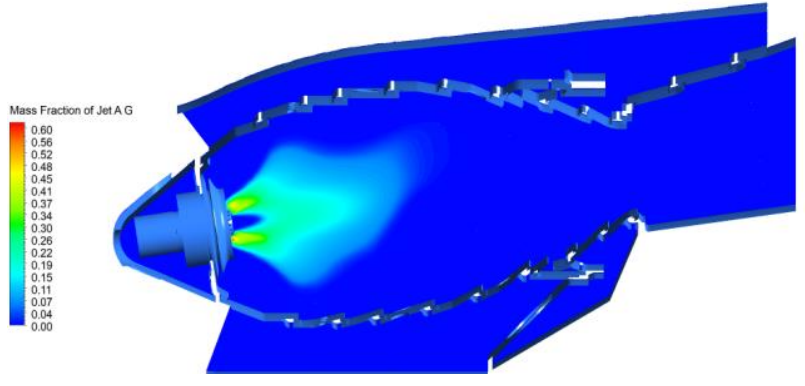

Секторная неравномерность $50 \%$

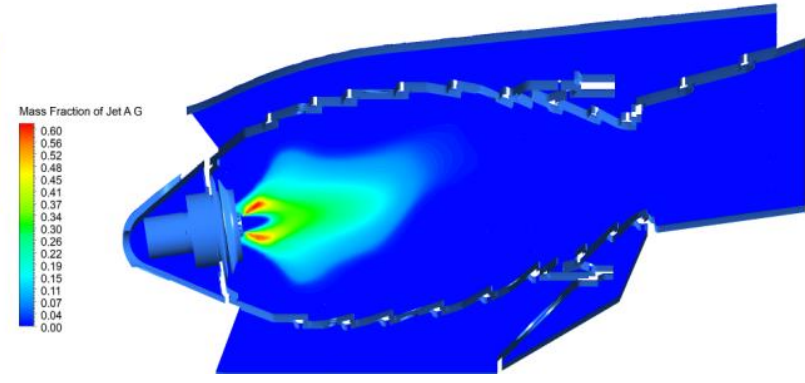

Коксование отверстий в колпачке завихрителя

Рис. 10. Изолинии концентрации топлива в меридиональном сечении КС

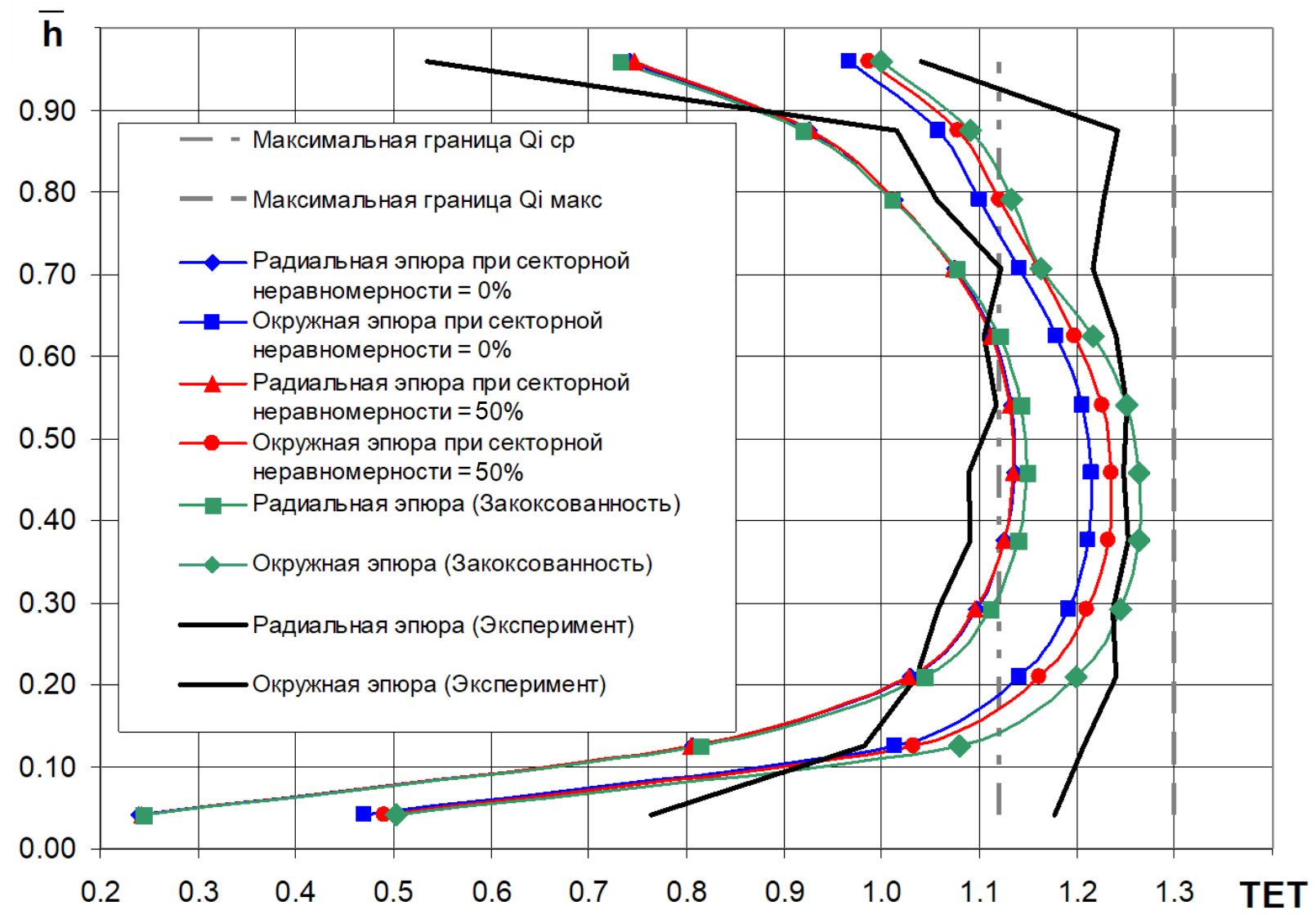

Рис. 11. Результаты моделирования радиальной и окружной неравномерностей поля температур газа на выходе из КС 


\section{Выводы}

По результатам численных исследований можно сделать следующие выводы:

1. Окружная неравномерность распыла топлива форсункой в пределах, допустимых конструкторской документацией (не более $50 \%$ ), оказывает не существенное влияние на значение радиальной эпюры газа на выходе из КС. При этом коксования отверстий колпачка завихрителя увеличивает значение радиальной эпюры на 1,2 \%, что является удовлетворительным.

2. Окружная эпюра газа на выходе с камеры сгорания увеличивается с ростом секторной неравномерности распыла топлива. При секторной неравномерности 50 \% максимальное значение окружной эпюры выросло на 1,6 \%, а при коксовании отверстий колпачка завихрителя на $4 \%$ по сравнению с секторной неравномерностью $0 \%$, что в свою очередь не превышает значение максимальной границы окружной неравномерности.

\section{Литература}

1. Распьливание жидкостей [Текст] / В. А. Бородин, Ю. Ф. Дитякин, Л. А. Клячко [и др.]. - М. : Машиностроение, 1967. - 262 c.

2. Лефевр, А. Процессы в камерах сгорания ГТД [Текст] / А. Лефевр. - М. : Мир, 1986. - 566 c.

3. Yevsieiev, S. Increasing Accuracy of the Gas Temperatures Pattern Calculation for GTE Combustor Using CFD [Text] / S. Yevsieiev, D. Kozel, I. Kravchenko // Integrated Computer Technologies in Mechanical Engineering - 2020. ICTM 2020. Lecture Notes in Networks and Systems, 2021. - vol. 188. Springer, Cham. DOI: 10.1007/978-3-030-66717-7_37.

4. Лубков, Н. В. Влияние характеристик контроля на показатели надежности систем [Электронный ресурс] / Н. В. Лубков, И. Б. Спиридонов, А. С. Степаняни // Труды МАИ. - 2016. - № 85. Режим доступа: http://trudymai.ru/ published.php?ID=67501. -12.04 .2021 .

5. Влияние экологических нормативов на развитие авиаџионного двигателестроения [Электронный ресурс] / Л. Б. Метечко, А. И. Тихонов, А. Е. Сорокин [и др.] // Труды МАИ. - 2016. - № 85. - Режим достуnа: https://www.mai.ru/ published.php?ID=67495. - 12.04.2021.

6. Костюк, В. Е. Анализ точности численных оценок перепада давления на ЖТ, распределения расхода воздуха по отверстиям ЖТ, коэффициентов расхода отверстий ЖТ и неравномерности поля температур на выходе КC, достигнутой другими авторами, а также использованных ими методических приёмов. Выполнение тестовых численных расчётов коэффициента расхода отверстия в тонкой стенке на сетках с различным разрешением и анализ их точности. Формирование выводов $u$ гипотез: Рабочие материаль этапа № 1. ТС № 65 oт 28.12.2009 [Текст] / В. Е. Костюк, Е. И. Кирилаш, А. А. Конопленко. - Харьков, 2009. - 159 с.

7. Костюк, В. Е. Формирование численных моделей, пригодных для оченки эффективности конструктивных мероприятий, направленных на оптимизацию характеристик КС по неравномерности поля температур на выходе КС: Рабочие материальг этапа № 5. Договор № 203-22/06 от 28.04.2006 [Текст] / В. Е. Костюк, Е. И. Кирилаш, А. А. Конопленко. - Харьков, 2009. - 39 с.

8. Механика жидкости и газа [Текст] / С. И. Аверин, А. Н. Минаев, В. С. Швылкий [и др. ]. - М. : Металлургия, 1987. - 304 c.

\section{References}

1. Borodin, V. A., Ditjakin, Ju. F., Kljachko, L. A., Jagodkin, V. I. Raspylivanie zhidkostej [Atomization of liquids]. Moscow, Mashinostroenie Publ., 1967. $262 \mathrm{p}$.

2. Lefevr, A. Protsessy $v$ kamerakh sgoraniya GTD [Processes in the combustion chamber of a gas turbine engine]. Moscow, World Publ., 1986. 566 p.

3. Yevsieiev, S., Kozel D., Kravchenko, I. Increasing Accuracy of the Gas Temperatures Pattern Calculation for GTE Combustor Using CFD. In: Integrated Computer Technologies in Mechanical Engineering - 2020. ICTM 2020. Lecture Notes in Networks and Systems, 2021, vol. 188. Springer, Cham. DOI: 10.1007/978-3-030-66717-7_37.

4. Lubkov, N. V., Spiridonov, I. B., Stepanyants, A. S. Vlijanie harakteristik kontrolja na pokazateli nadezhnosti sistem [Influence of control characteristics on indicators of system reliability]. Trudy MAI, 2016, no. 85. Available at: http://trudymai.ru/ published.php?ID=67501. (accessed 12.04.2021).

5. Metechko, L. B., Tihonov, A. I., Sorokin, A. E., Novikov, S. V. Vlijanie jekologicheskih normativov na razvitie aviacionnogo dvigatelestroenija [Influence of environmental standards on the development of aircraft engine building], Trudy MAI, 2016, no. 85. Available at: https://www.mai.ru/published.php?ID=67495 (accessed 12.04.2021)

6. Kostyuk, V. E., Kirilash, E. I., Konoplenko, A. A. Analiz tochnosti chislennykh otsenok perepada davleniya na ZhT, raspredeleniya raskhoda vozdukha po otverstiyam ZhT, koeffitsientov raskhoda otverstii ZhT $i$ neravnomernosti polya temperatur na vykhode $K S$, dostignutoi drugimi avtorami, a takzhe ispol'zovannykh imi metodicheskikh priemov. Vypolnenie testovykh chislennykh raschetov koeffitsienta raskhoda otverstiya $v$ tonkoi stenke na setkakh $s$ razlichnym razresheniem $i$ analiz ikh tochnosti. Formirovanie vyvodov $i$ gipotez: Rabochie materialy etapa № 1. TS № 65 ot 28.12.2009 [An analysis of the accuracy of numerical estimates of the pressure difference across the flame tube, the distribution of air flow over the openings of the flame tube, the flow coefficients of the openings of the flame tube, and the unevenness of the 
temperature field at the exit of the combustion chamber, achieved by other authors, as well as the methods used by them. Test numerical calculations of the flow coefficient of the hole in the thin wall on grids with different resolutions and analysis of their accuracy. Formation of conclusions and hypotheses: Working materials of stage No. 1. Technical information No. 65 of 12.28.2009]. Kharkov, 2009. 159 p.

7. Kostyuk, V. E., Kirilash, E. I., Konoplenko, A. A. Formirovanie chislennykh modelei, prigodnykh dlya otsenki effektivnosti kon-struktivnykh meropriyatii, napravlennykh na optimizatsiyu kharakteristik KS po neravnomernosti polya temperatur na vykhode KS:
Rabochie materialy etapa № 5. Dogovor № 203-22/06 ot 28.04.2006 [Formation of numerical models suitable for assessing the effectiveness of structural measures aimed at optimizing the characteristics of the compressor by the uneven temperature field at the output of the compressor: Working materials of stage No. 5. Contract No. 203-22 / 06 of 04/28/2006]. Kharkov, 2009. 39 p.

8. Averin, S. I., Minaev, A. N., Shvydkii, V. S., Yaroshenko, Yu. G. Mekhanika zhidkosti i gaza [Fluid and gas mechanics]. Moscow, Metallurgija Publ., 1987. $304 \mathrm{p}$.

Поступила в редакцию 10.05.2021, рассмотрена на редколлегии 16.08.2021

\section{РОЗРАХУНКОВА ОЦІНКА ВПЛИВУ НЕРІВНОМІРНОГО РОЗПИЛУ ПАЛИВА НА ПОЛЕ ТЕМПЕРАТУР ГАЗУ НА ВИХОДІ ІЗ КАМЕРИ ЗГОРЯННЯ ГТД}

\section{A. Свсесв}

У даній роботі представлені результати чисельного моделювання течії газу з горінням розпилу рідкого палива (використовувалася модель рівноважного горіння pdf поряд з моделлю частково перемішаної суміші) в кільцевій камері згоряння газотурбінного двигуна. Чисельне моделювання виконувалося в розрахунковому комплексі ANSYS Fluent. Метою розрахунків була оцінка впливу нерівномірності розпилу палива заданої в конструкторської документації та коксування деталей фронтового пристрою на радіальну та окружну нерівномірність поля температур газу на виході $з$ камери згоряння. При моделюванні використовувалася раніше верифікована модель турбулентності k-e з функціональною залежністю турбулентного числа Шмідта Sс від температури газу яка була реалізована в розрахунковому комплексі ANSYS Fluent за допомогою функції користувача (UDF). У зв'язку з тим, що паливна форсунка та завихритель, представляють досить складну схему розпилювання, що не дозволяє розрахунковим шляхом оцінити кількість палива, що надходить через отвори в ковпачку завихрителя було виготовлено установку та проведені випробування по визначенню кількості паливо-повітряної суміші, що розподіляється по отворах ковпачка завихрителя. Експериментальні значення розподілу паливо-повітряної суміші через отвори в ковпачку завихрителя в подальшому використовувалися для виконання чисельного моделювання горіння в камері згоряння. Чисельне моделювання проводилося з секторною нерівномірністю рівною $0 \%, 50 \%$ (максимально допустима згідно конструкторської документації) та при коксуванні отворів ковпачка завихрителя. В результаті проведених розрахунків встановлено, що секторна нерівномірність 50 \% надає не істотний вплив по відношенню до секторної нерівномірності $0 \%$ на радіальну нерівномірність поля температур газу на виході 3 камери згоряння, при цьому окружна нерівномірність на виході з камери згоряння виросла на 1,6 \% по відношенню до секторної нерівномірності $0 \%$. При коксуванні отворів ковпачка завихрителя значення радіальної епюра на виході з камери згоряння збільшується на 1,2 \%, а значення окружної нерівномірності збільшується на $4 \%$.

Ключові слова: розпил палива; секторальна нерівномірність; камера згоряння; турбулентне число Шмідта; поле температур газу; комп'ютерне моделювання; UDF; ANSYS Fluent.

\section{CALCULATED ESTIMATION OF THE INFLUENCE OF INFORMALITY OF THE FUEL SPRAY ON THE FIELD OF GAS TEMPERATURES AT THE OUTLET OF THE COMBUSTION CHAMBER OF A GTE}

\section{S. Yevsieiev}

This paper presents the results of numerical simulation of a gas flow with the combustion of atomized liquid fuel (the equilibrium combustion model pdf was used along with the model of a partially mixed mixture) in an annular combustion chamber of a gas turbine engine. Numerical modeling was carried out in the ANSYS Fluent computational complex. The purpose of the calculations was to assess the influence of the unevenness of the fuel spray specified in the design documentation and the coking of the parts of the front-line device on the radial and circumferential unevenness of the gas temperature field at the exit from the combustion chamber. The simulation used the previously verified turbulence model k-e with the functional dependence of the turbulent Schmidt number Sc on the gas temperature, which was implemented in the ANSYS Fluent computational complex using the user function (UDF). Since the fuel injector and the swirler represent a rather complex spraying scheme, which does not allow calculating the amount of fuel entering through the holes in the swirler cap, an installation was made and tests were carried out to determine the amount of the fuel-air mixture distributed over the holes in the swirler cap. The experi- 
mental values of the distribution of the air-fuel mixture through the holes in the swirler cap were further used to perform numerical simulation of combustion in the combustion chamber. Numerical modeling was carried out with sector non-uniformity equal to $0 \%, 50 \%$ (the maximum allowable according to the design documentation), and during coking of the swirler cap holes. As a result of the calculations, it was found that the sector irregularity of 50 $\%$ has an insignificant effect concerning the sector irregularity of $0 \%$ on the radial irregularity of the gas temperature field at the exit from the combustion chamber, while the circumferential irregularity at the exit from the combustion chamber increased by $1.6 \%$. to the sectorial unevenness $0 \%$. When coking the holes of the swirler cap, the value of the radial diagram at the outlet from the combustion chamber increases by $1.2 \%$, and the value of the circumferential irregularity increases by $4 \%$.

Keywords: fuel spray; sector irregularity; combustion chamber; turbulent Schmidt number; gas temperature pattern; computer simulation; UDF; ANSYS Fluent.

Евсеев Сергей Анатольевич - инженер-конструктор 1 категории расчетно-экспериментального отдела камер сгорания ГП «Ивченко-Прогресс», Запорожье, Украина.

Serhii Yevsieiev - engineer-designer of the 1st category of the Calculation and Experimental Department of Combustion Chambers, SE "Ivchenko-Progress", Zaporozhye, Ukraine, e-mail: EvseevSA@ivchenko-progress.com, ORCID: 0000-0001-5231-0826. 